\title{
The Role of Water in Persian Gardens
}

\author{
Jamal-e-Din Mahdi Nejad, Hamidreza Azemati, Esmaeil Zarghami, Ali Sadeghi Habib Abad*
}

Department of Architecture, Shahid Rajaie Teacher Training University, Tehran, Iran

Email: *a.sadeghi@srttu.edu

How to cite this paper: Mahdi Nejad, J., Azemati, H., Zarghami, E. and Abad, A.S.H. (2017) The Role of Water in Persian Gardens. Open Journal of Ecology, 7, 41-54. http://dx.doi.org/10.4236/oje.2017.71004

Received: May 12, 2016

Accepted: January 20, 2017

Published: January 23, 2017

Copyright $\odot 2017$ by authors and Scientific Research Publishing Inc. This work is licensed under the Creative Commons Attribution International License (CC BY 4.0).

http://creativecommons.org/licenses/by/4.0/

\begin{abstract}
The role of water in the formation of the first human habitats is a response to a biological need. But when above a need, home building and constructing residential complexes have a cultural meaning, architecture is emerged and water in human life has an artistic place and it is originated from the creativity of the artists and architects. Understanding the concept of water in architecture is understanding the concept of water architecture. Understanding the physical laws of water behavior is our emotions to the interaction of water and most importantly the role and allegory and its relationship with human life. Water is a paradoxical metaphor and along with soil, fire and air, consists of the four comprising elements of the universe. If someone asks us to define water, we say it is a colorless liquid which is the source of life, but is it really the definition of water in architecture and only in terms of the physical aspect, it is an interface between man and architecture? To answer this question, first we examine the available resources in this field and desk studies about the architectural spirit and then examine the water hidden side and the way it affects humans and architecture through descriptive-analytical method, so by contemplating in them, the question can also be answered. From the beginning, water was a vital element not only for the body but for the soul.
\end{abstract}

\section{Keywords}

Persian Gardens, The Role of Water, Psychology of Water, Water Concepts in Persian Garden

\section{Introduction}

Building gardens has a long history in our country and has been considered in all eras, especially the Islamic period. Gardens had several performances and in some era, public gardens were constructed for travel and leisure time of residents. According to archaeological findings, the first garden to form four-garden taken shape in Iran is the garden Pasargadae, which was built by Cyrus the Great (550-330 BC). 
In Islamic period, building gardens and woodlands was still favorite to inhabitants of this ancient land. In addition to large and magnificent gardens out of the cities, gardening phenomenon in and around cities has been special to this land for several centuries. In Islam, tree planting is good and its unnecessary cut is reprehensible. There are many narrations in this case.

The Holy Qur'an has several references to heaven and its lush and beauty.

For example, a few verses of Surah Ar-Rahman are as follows:

[They are] reclining on beds whose linings are of silk brocade (Number Verse of in the Quran 54) [1].

Water is also a key element of the Persian Garden and at least three conceptual, functional and aesthetic aspects are present in the garden. These aspects can easily be followed in topics such as the presence of water in garden and its movement and cycle, water supplies and garden irrigation. In most cases, aqueducts or fountains were the main sources of water supply for gardens and in many cases, the water and its management and division which were done precisely in past, determined the area of garden. How to irrigate the gardens, which is in direct contact with the shape and type of land in Persian Garden, is important and of course due to the water shortage in most parts of Iran as well as the sanctity and respect for water in the past and Iranian great interest in the use of water in gardens, has caused them to move water in various ways in the garden and add on its beauty and elegance. Plants in Persian Garden, besides the genus and species, are very impressive in terms of location, planting design, beauty and usefulness and even play a role in the protection of garden against destructive natural factors.

\section{Methodology}

For a long time, human beings are always trying to meet their needs through exchange of information, visually, auditory and written and for realization of dialogue between human beings, which prerequisite is the existence of common subject and language, the principle of mutual understanding should be considered [2]. So, classifying articles to different types makes each person find his own audience. In a classification, reports are included in two social and professional categories which the first is the inclusion of reasoning and critical forms and the latter covers research and review [3]. Thus, this paper is in expert and review area. In fact, each system of search includes general structure and partial techniques. There should be coherence and continuity among all of those areas [4]. With this interpretation, the research methodology is qualitative-descriptive.

\section{Persian Gardens}

Persian Garden is the oldest and most important gardens in the world. Persian garden is mostly indicative of psychological needs and less measurable with water requirements. Since ancient times, it was an essential part of Iranian life and its architecture and contributed in the presence of large temples and their symbolic strength. Since Sumerians, gardens surrounded the temple and the royal 
palace. Life in Iran is dependent on water and the water is in fact the main factor of life. Iranians have drawn a tree with running water which is the most favorable views in a dry land. After water, trees play the most important role in the formation of Persian Garden. Ancient Iranians believed in a sacred angel called Aororoza that hurting the plants would made her upset and angry. Much earlier than other nations, Iranian found that creating gardens is the basis for agriculture and achieved the best practices of building gardens since ancient times. In the Islamic era, huge gardens surrounded the palace, and were considered as part of its architecture, so that the garden covered all main aspects of the building symmetrically. The area was divided into rectangular pieces that small streams passed through them. The gardens were built according to the Iranian predecessors and from the first centuries $\mathrm{AD}$, Iranian-style garden goes beyond borders and widens its scope over time. The garden building method in the eastern countries were inspired by Iranian garden building, in Islam, planting trees was good and unnecessary cut them was considered reprehensible and there are many verses and narrations in this case.

\section{Geometry of Water in the Garden}

In Iranian garden, special attention is paid to geometric shapes and square which shows the distance between the components simple and clear, was of great importance [5]. At the time of planting a tree, the first step is precise in determining the distance from each side and thus forming squares that looking from each side, rows of trees could be seen [6].

Therefore, the general pattern of most Persian gardens consisted of a rectangular space which is quartered by intersecting streams and pathways [7]. The common irrigation system of the time has been known as another effective factor in the formation of geometric garden structure besides the impact of Persian beliefs and morals [8].

This is in addition to directing the flow of water and avoid wasting it, results in rise of the exact order of how planting trees. So, outer boundary of the garden, water flow paths, fountains' location, terracing, the planting system of trees and plants, the location of the palace and garden buildings, have been determined based on precise geometrical structure.

Beginning to water from inside the palace to garden and its extension in space seems that one feels the main route of water passed through the pavilion.

Sound of water in garden space was done by fountains, small waterfalls and ripple marks.

\section{Iranian Gardens' Architecture}

Building gardens have a long history in our country and have been considered in all eras, especially the Islamic period. Gardens had several performances in general and in some eras, public gardens were constructed for travel and leisure time of residents. During the Islamic period, creation of gardens and woodlands was also of interest for inhabitants of this old land. In addition to large and 
magnificent gardens out of the cities, phenomenon of building gardens in and around cities has been special for this land for centuries. In Islam, tree planting is good and its unnecessary cutting is reprehensible, and there are various traditions in this case. On the other hand, due to climatic differences in various regions of Iran, especially in tropical regions, garden is particularly important. These two issues and other issues caused the tree to be respected as a plant and vital factor by the people. In fact, the Iranian culture doesn't separate man from nature, but sees him along with evolution of natural elements to discover the signs of God [9].

\section{Elements of Persian Gardens}

In the gardens, or in other words, discipline is the elements of natural, manmade and put together and how the use of natural elements, and select characteristics of their discipline, how to take advantage of them, and their relation with everyday life of people, play a central role. Some elements of Persian Gardens have been used include: (ground), (water), (plant) and (space), once the intellectual system of Persian architecture and a framework concept and idea of the garden are together form (garden). In this way, other elements may be used in the creation of the gardens, which are minor elements or component parts, and the effects of the main elements of garden (Figure 1).

\section{Water beyond Material Needs}

Water is a world used in speaking always and everywhere and if someone asks us to define, we say it is a colorless liquid which is the source of life, but is it really the definition of water in architecture and only in terms of the physical aspect, it is an interface between man and architecture? Or like the two hides something within itself to be beyond their origin and material?

To answer this question, we first examine the human psyche and then the architectural spirit and then we examine the water hidden side and the way it affects humans and architecture, so by contemplating in them, the question can also be answered.

Water in the art has a high status and is remembered as a symbol of life, purity, joy and light and is of great importance in rituals of grief and joy. Different states of water create different feelings of the inhabitants of the planet and everyone according to his age takes his own psychological advantage. Arts from the water are apart from the thoughts and beliefs of Iranians. Understanding the concept of water in architecture or water architecture, depends on understanding of water physical laws, our feelings to interactions of water, and most importantly, the role, allegory and communication with human life. Water symbolizes all things that exist potentially.

Interpretations and meanings in relation to water somewhat has a close bond with its inherent meaning and its vital role. Water is the messenger of light and purity and is of great value.

In addition that water moves people beyond, but also wherever it appears, it 


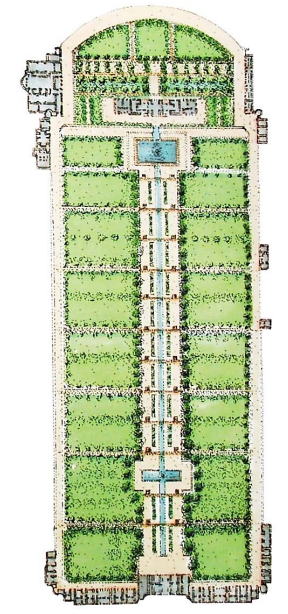

(a)

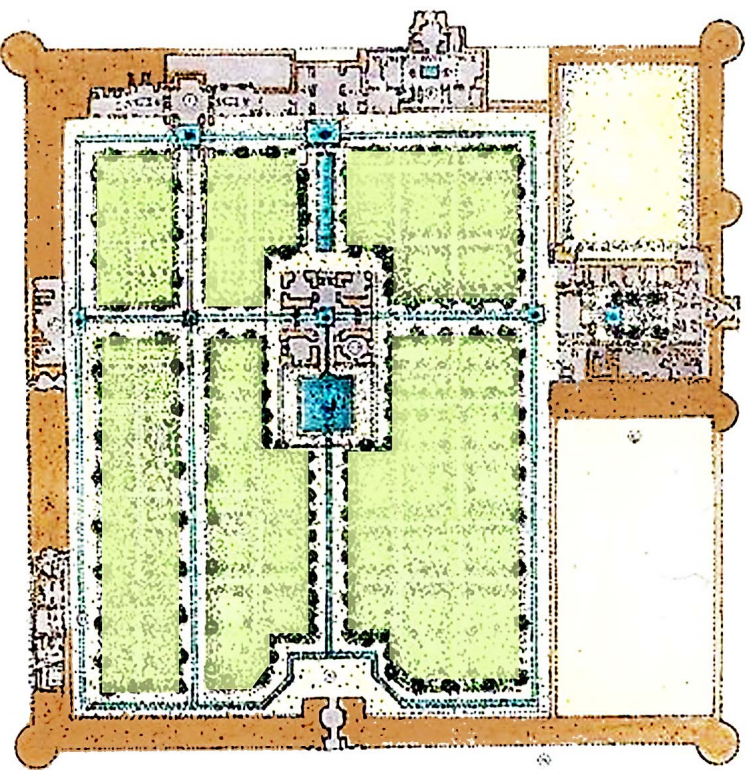

(b)

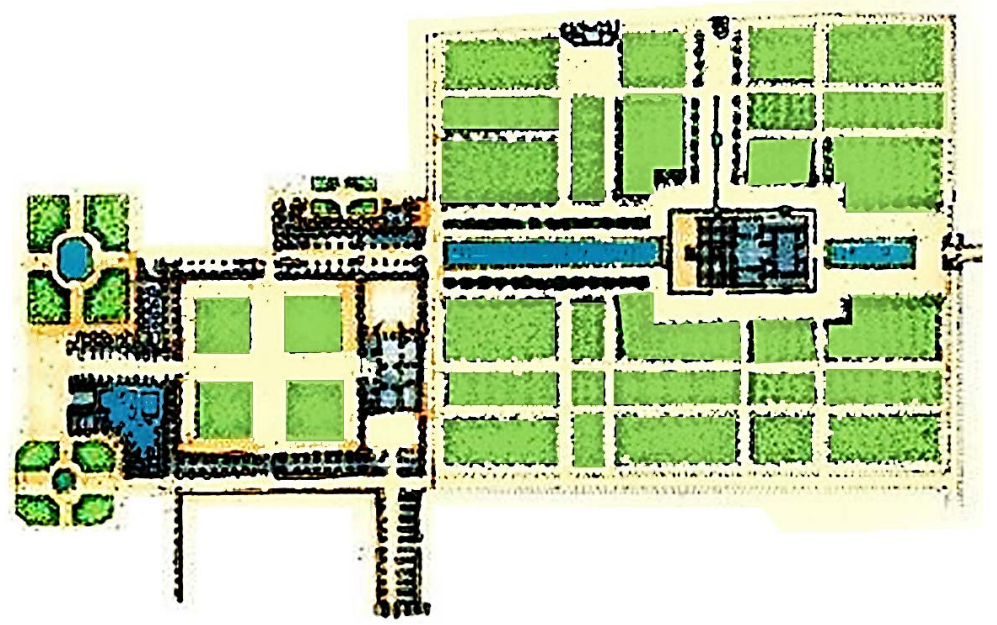

(c)

Figure 1. The geometrical structure of Persian garden Plan. (a) Shahzadeh-Mahan Garden, Kerman [10]; (b) the Plan of Fin Garden, Kashan [11]; (c) the Plan of Chehel Sotun Garden, Esfahan (Khansari et al. 1998) [11].

reflects the architects' perception of nature. Water makes human sees the nature around and feels it by simulating the visual, auditory and tactile powers and understands the concept of place precisely with composition and the conflicts with the nature.

\section{Sensory Value of Water and Its Effect on the Human Psyche}

\section{Color}

Water is the most important and critical element which forms garden because birth and life of garden will be meaningless without its presence. After water, plants play the most important role and their flow is rooted in water [12]. Shape 
and presence, movement and flow of water in the garden have a special system coordinated with geometry and its architectural structure [13].

Water has always no identical state, and every time, it finds a new look. Change of seasons and hours in every moment makes water in a different color. While character of water particles is involved in determining its color.

Water is the source of all the sounds and each is the creator of a different feeling in man's heart (effective on the human psyche!). Inspired by nature, man enters these different musical rhythms of water into the architectural space of his life and made it the music of his soul. The music not only caused spirit gratification but also was used as treatment.

\section{The Role of Water in Beliefs}

Geometry of Persian gardens is not only owing to the irrigation and agriculture principles, but also it is formed due to the beliefs, meaning, symbols, myths and the elements that form the Persian garden's identity [14]. The early geometric form of the garden might be dictated by the practicalities of the irrigational system [15].

Water links the earth and sky. It is the symbol of freshness, brightness, life, innocence and so on. As a holy and sacred element, water has been of particular esteem among many cultures and civilizations from ancient times. Water in Iran has long been beside the fire, which both have a close bond with life and it is linked with water protector, fertility and blessing.

In Greek mythology, all running waters and springs had an Izadani woman called nymphs. Water is sacred to the extent that even in religions, creation begins with water. In genesis it is said that: "And God said there should be a sky in the waters to separate water and God constructed it..." Of course, the fact that heaven and earth were formed from water is rooted in ancient mythology. For example, Babylonian tablets stated that the universe was a thick mass of water.

Water as an important factor also had a special place in different religions.

In the Avesta, water was frequently respected and in Yasna 65 part 10 Ahura Mazda Zarathushtra was addressed: "First turn to water and ask your needs from Zarathustra". It is understood from the Islamic narrations that God created all the world entirely with water. The Quran says: "and made from water every living thing." In general, water always plays a role in the creation, mythology, religion, iconology, apart from the cultural structures, it is above all forms and is the patron of any creation... water is a key to life by considering the potential facilities.

In every place and time where water is sacred, some sites (the architecture formation) have been formed for its appearance to enable achieving the ultimate goal.

\section{The Role of Water in Architecture}

The role of water in the formation of the first human habitats is a response to a biological need. But when more than a need, building home and residential 
complexes have cultural meaning, architecture is emerged and water in human life will have an artistic place and is originated from creativity of the artists and architects. Understanding the concept of water in architecture is understanding the concept of water architecture. Understanding the physical laws of water behavior is our emotions to the interaction of water and most importantly the role and allegory and its relationship with human life. Water is a paradoxical metaphor and along with soil, fire and air, consists of the four comprising elements of the universe. Water is considered as one of the natural elements that has anmutable nature. Wherever it appears, its application should reflect the perception of designers and builders of nature. Access to water resources has long been one of the most important factors in urban locating. Iran's geographical overview cities show the dependency between urban life and access to water resources. Iranian plateau, due to climatic diversity and natural environment landscape has no reliable surface water sources everywhere, because as surface water, such as sea, rivers and lakes play a role in the architecture and the its creation, in many regions that are far from these surface resources, people need is met from underground sources, such as canals and wells.

Riverbanks are the bed of the emergence and growth of the world's most ancient cultures. In Iran, where a river was flowing, the speed and cultural acceleration was added and it is also expanded in culture. It should be noted that water in the very distant past caused vital places and economic and urbanism ways.

Before the advent of Islam in Iran, architecture besides the water and in the nature without distorting, announced its presence and the role of water is mostly abstract role. Temples and shrines are formed besides the water and in respect to water. As water is the path of man to enter another world. Water showed its spiritual role in Iranian architecture, so that the water cycle is its abstraction representation in nature and all properties of water is abstract which apparently finds a dramatic aspect and water was considered in prayer. So, the rivers and streams and lakes had a place in the beliefs and customs. This was not formed per se. Construction and building sites has manifested beliefs, legends and customs. Waters which originated from the mouth of the great mirage of a mountain and in a cave or among the rocks and soil and flowed on the ground, are large and small springs that originate out of stone and play an important role in the construction of buildings around them. And here we see that both water and rock are involved in the construction of buildings. As the water plays a role in the construction of the garden, the garden also plays a role in the development of the city. The development of towns and structural relationship between the garden and the city is such that we can call the garden as city and call the garden city and on the other hand garden is regarded as a workshop for designing city that the sample can be seen in Timurid period which showed the structural relationship between the garden city in the temporary city which reconstructed the length of tents, pavilion and encampment clearly.

Another example of this garden city can be seen in Isfahan and Chahar Bagh and the alleys that were continued in different directions, it was one of the prin- 
ciples of urban landscape design.

In ancient Persia, the architecture moves to water and is calm besides it. But in the Islamic period, water had an applied state in architecture and architects consciously try to dominate nature and organize it and with knowledge of physical laws and behavior of water and understanding the role and allegory and its relationship to human, drags the water inside the architecture. Water is manifested in geometric shapes in most buildings and somehow the center of architectural unity is formed in water. Its wavy motion in religious, literary and artistic concepts is common in our culture. So it enters the building and composition of our monuments so that cannot practically be separated from shape. Water will appear in the center of palace and gardens, etc. In the desert, scarce and lifeshaping water causes formation of architecture of water reservoirs, downstream and Ribat and the glaciers, and shows itself in other way.

Water in the garden and pavilion creates streams, waterfronts, ponds and pools and fountains and every word illustrates the human domination of nature (Figure 2, Figure 3). To display all of them on its side, water in the pool architecture is used as a symbol of standing water and in regular geometric is the element of building completion. Water use in Iranian garden has been very clever and artistic, so not only is used for watering and feeding plants of the garden, but also its conceptual, poetic and artistic use decorated the garden space and with its presence brings freshness, vitality, movement and beauty [16].

Pools in front of the buildings complement the architecture and reflect them as a mirror. Ponds we observe in mosque architecture, beyond the role of purification, has a symbolic aspect and water created both the symbol of life and death. And purifies man both physically and mentally and generally understanding the concept of water in the architecture is understanding the water architecture.

\section{The Role of Water in Ancient Iranian Architecture}

Water in ancient Persia was a messenger of light and purity and was of great value. Since Iran was probably a low water country, the vital fluid had high prestige among them. Water for Iranians was used not only for meeting their needs,

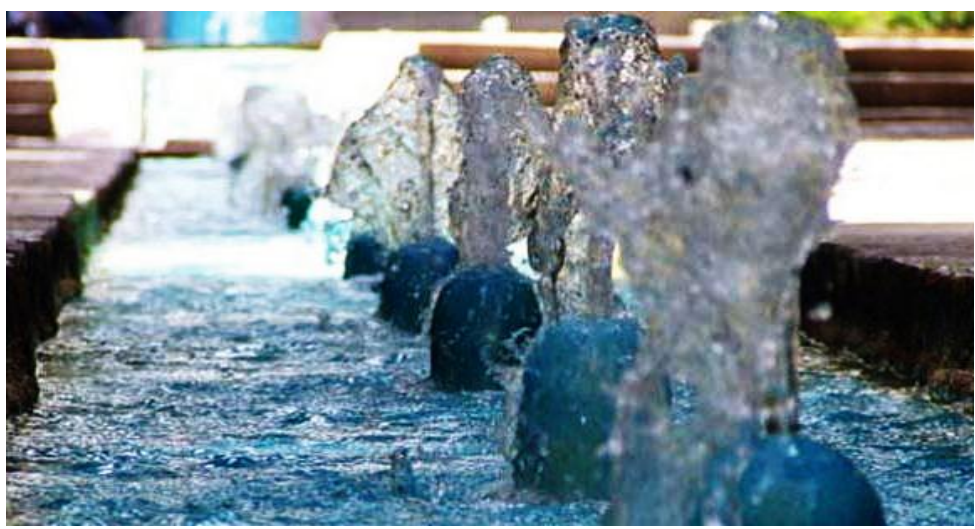

Figure 2. The rows of fountains in Fin Garden in Kashan, Isfahan, Iran [17]. 


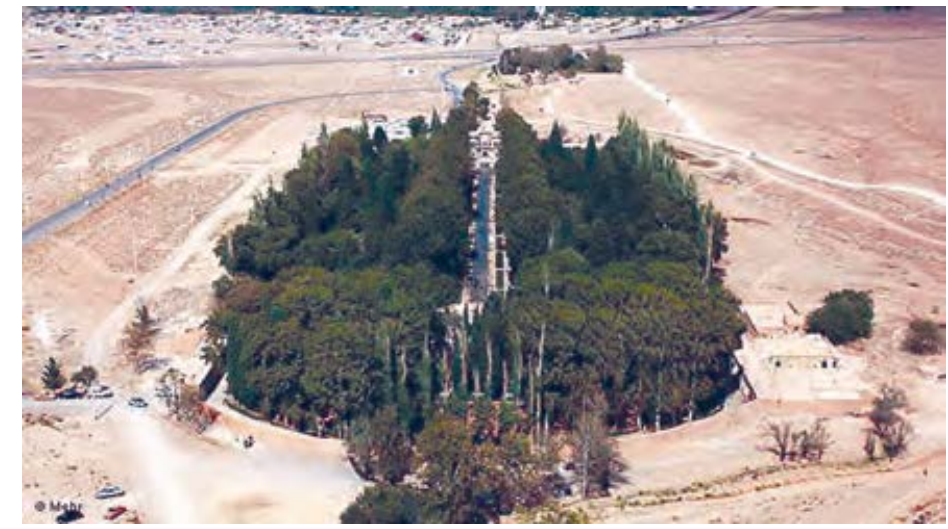

(a)
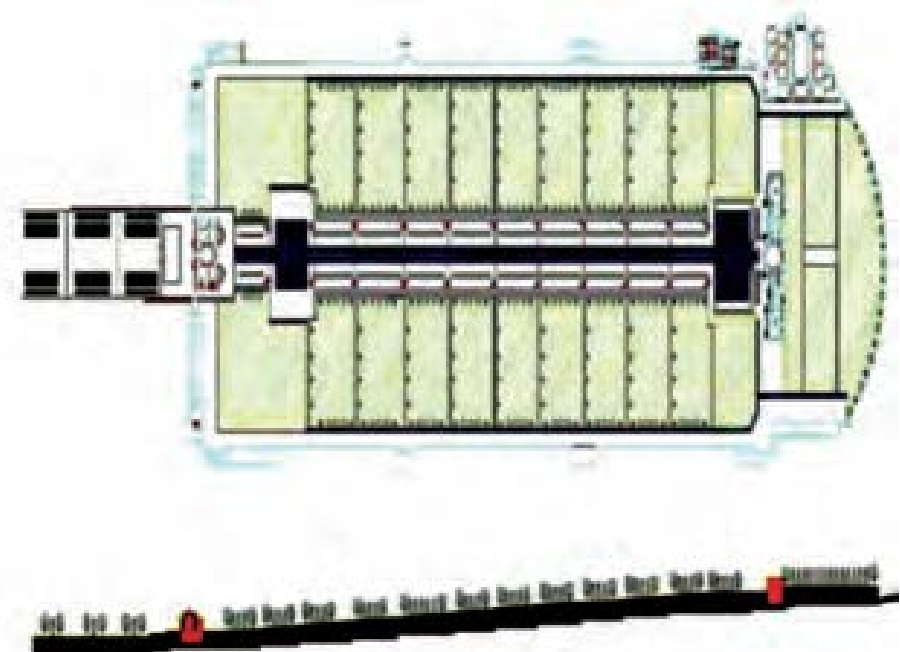

(b)

Figure 3. Water as the main element in Persian garden, Bagh-e-Shazdeh pools and water channels [18].

but also had very influence spiritually and mentally. Water with different capabilities, such as life, freshness, brightness, cleanliness, prosperity and spreading the light, rest and relaxation and mobility left various feelings in the psyche of mankind. For this reason, it finds a place always in places that are man-made in different ways. This is more impressive in relation to places like parks or gardens. Because water element is used as one of the most beautiful fields of view and one of the complementary items of green space. Of course, in these places, water is necessary and important for cleaning and irrigation of trees and flowers or for health services.

In previous centuries, Iranians constructed gardens on sloping lands and creating a stair in the water path, gentle stream of water became harsh and noisy. The main factor that always gave life to the Iranian gardens was water flowing in Chahar Bagh, streams and low-slope and spiral streams and made the garden air pleasant. In decorative garden joining the ponds, streams were usually built with stones and bricks. In floor of front waters and most places where the water was flowing, often placed a rock with white cutting or with different designs that 
gave a beautiful aspect to water wave. The ancient gardens of Iran are often built in hot and dry regions, and reason for their establishment in such areas was the presence of natural springs or Kariz.

The extent of any garden depends on the volume and the amount of water available for irrigation. Due to the warm weather in summer, gardens in arid and desert cities have always had a special importance among which are gardens of Kashan (Figure 4). Fin Garden in Kashan is the famous gardens of the Safavid, Zand, and Qajar as well as our time. Due to the abundance of water in Soleimani spring and pool and many fountains and old trees and historical buildings, has always been one of the most famous and the most attractive gardens in our country.

In Iranian gardens, to create a calm, cool and shade environment, there was no choice but to build streams of water throughout the whole garden and usually the streams were converted to basins at the intersection. Water flowed to the ponds from rivers that often began from springhouse of garden mansion and at regular intervals using the natural slope of the land with repetition of waterfalls. Front water that was considered the essential elements in building garden, was mostly constructed in front of the main building and its main aspect is align with the length of building and was in various forms: rectangles, squares, polygons and circle. Sometimes, fountain was made in buildings of old gardens in terms it was said spring house. Residents of the garden on hot summer days, especially during midday, were relaxed along waterfronts.

\section{The Hierarchy of Water Presence in the Garden}

The presence of water in the garden has three steps:

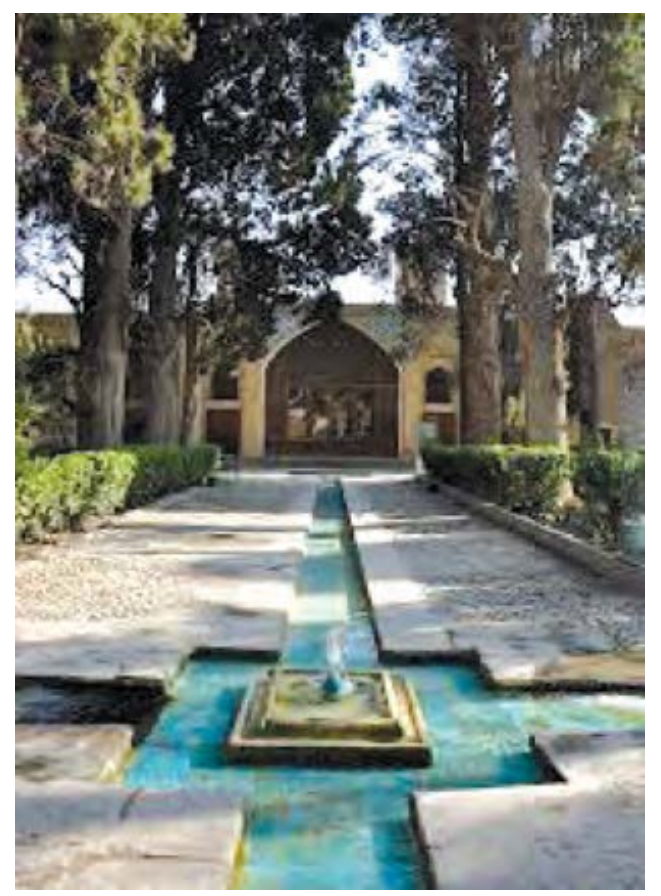

Figure 4. Fin Garden in Kashan, Isfahan, Iran [19]. 
First step is entry of water into the garden.

Second step is presence of water in the garden and the last step is exit of water from garden.

Knowledge of water resources is necessary to analyze its presence in the garden. At this stage, water has two functional and symbolic functions that is, from the functional point of view, it irrigates trees and plants and creates freshness in the space and from the symbolic aspect, it is expressed as a specific concept as a view for meeting which in fact, it responses the need to understand its existence.

In the second step, it is necessary to identify the tools used to display the presence of water in the garden to achieve the design and facilities used.

Water flows in paths in a wise and intelligent way. It remains still in ponds and fountains, rises above the water of sags and fountains and manifests with movement, sound, facade and refreshing [20]. How to present and move for water in garden has a certain system in accordance with the geometry and structure of the garden and takes different forms in the different species of Persian garden [21].

In the last step, water goes out of the garden, so that after flowing in garden and irrigating the trees and plants, it goes to the city, farms or other gardens. After leaving the garden or at surface, the water moves toward the destination as river or stream or in underground using special channels and using water pipes.

\section{Water and Psychology}

The human is a set of spirit, mind and body. As the human body needs food, his mind and soul needs elements that give him peace. In the city which tall buildings, streets and machine life surround everywhere, the effects of beauty and art are the best refuge for man tired and comfort-seeking soul. Today, in cities we witness elements with hard contexts such as concrete etc., instead of natural elements (vegetation) are. Therefore, by using elements of the soft tissue, we should provide hermitage and beauty to give peace to the human psyche. These places can be parks and urban gardens. Water is considered one of these elements and whether at rest or in motion caress the human soul. Water motion and music has a remarkable role in more reflection of green space. Water can be designed in the form of streams and springs for the quiet places and as large waterfall and fountains for crowded and busy points. Water is actually the most interesting subject in landscape and sweetest event in different parts of a garden [22].

\section{Water and Still Water Surface Reflection}

By reflecting light, it acts like a mirror, and shows the phenomena surrounding itself with a 180-degree view, and also a reflection of vegetation in the water and sunlight on aquatic plants in the water creates a beautiful picture for the audience. Moving water reflects light waves in space, like a light reflecting from a stream flowing on the leaves of the trees.

Water and its effect on decreasing temperature and increasing humidity: Wa- 
ter in parks and gardens in different forms, are somehow effective in balancing the air temperature, relative humidity supply for plants and create vibrant. The combination of these factors reduces the uniformity and environmental draught.

\section{The Flow System of Water in Garden}

Water flow in the garden can be divided into two ways: eruptive and smooth motion, so that in the Persian gardens, many examples can be found for these two types. Due to the use of these two methods (i.e. water directing as sideways and vertical eruption) in addition to the aesthetic and diversity-friendly aspect, it depends on the environmental conditions and type of the main elements contributing to the creation of the garden.

Factors such as the type of water source, slope, performance of surrounding spaces, and so on.

In the eruptive flow, water boils like a spring inside the pools or leaps upward using fountains and flowing movement, water is flown in streams and goes from river to river and flows in basins and on its way, creates waterfalls.

What is obtained from the analysis of water flow system in garden is that in its system, water in two modes tends to rise and fall and its' diversify of movement is based on these two modes.

So that in rotational mode (tendency to rise) used its volume pressure and at smooth motion (tendency to descend) took advantage of the force of gravity.

Thus, the flow of water in the garden can be divided in two parts, namely:

1) Water flow system under pressure

2) Water flow system under the influence of gravity

3) Water flow system under pressure

The reason for the eruption of water erupting flow is based largely on its volume pressure, so that when fluid accumulates in a source, upper layers impose a pressure on the lower layers, whereas the lower levels with certain channels are transferred to other parts, according to the pressure, they will have a spouting mode and tend to ascend.

\section{Conclusions}

In ancient Persia, the architecture moves to the water and is calm along with it. But the water in the Islamic period has an applied form in architecture and architects consciously try to master the nature and keep it in order and draw the water in architecture with the knowledge of physical laws and behavior of water and understanding its role, allegory and relationship with human. Water is appeared in geometric shapes in most buildings and centrality of architectural unity is formed in water. Its wavy motion is current in religious concepts and literary arts in our culture. So, it enters our building and monuments so that it cannot practically be separated from shape. Water appears in the center of the palace, garden and so on. In the desert, scarce and life-giving water results in the formation of architecture of water reservoirs, downstream, Ribats and glaciers, and manifests itself in another way. 
Water in the garden and pavilion creates streams, front waters, ponds, pools and fountains and each represents man dominance over nature to show all of them besides itself. Water in the pool architecture is used as a symbol of standing water and as regular geometric element is the building completion factor.

Ponds in front of buildings complement the architecture and reflect them as mirror. Ponds we see in mosque architecture, beyond the role of purification, have a symbolic aspect and create water symbolizing life and death; and purify man both physically and mentally and generally understanding the concept of water in the architect is understanding the water architecture.

\section{References}

[1] (2014) Holy Quran. Translator: Ali Meshkini, Qom-Hadi, The city of Qom, Iran.

[2] Azari Mobarakeh, B. and Habibi Savadkohi, M. (2014) Examining Examples of Different Kinds of Endogenous Expansion. Proceedings of the International Conference of Civil Engineering, Architecture and Urban Infrastructure, Tabriz, Iran, 2014, 1-12.

[3] Mirzaee, K. (2011) Scientific Manner of Essay Writing. Second Edition, Jame-e Shenasan Publication, Tehran.

[4] Mumford, L. (1989) The City in History. A Harvest Book Harcourt, New York.

[5] Goudarzi, S., Mehdi, M. and Mokhtabad, E. (2013) The Persian Garden Symbolism in Islamic Era. Hoviat Shahr Publication, No. 13, 55-63.

[6] Pirnya, M.K. (1994) Gardens of Iran. Written by Farhad Abvalzya, Abadi Magazine, No. 15.

[7] Borazjani, V. and Javadi, M.R. (2004) Persian Garden: Ancient Wisdom, New Perspective. Contemporary Arts Museum of Tehran Publications, Tehran.

[8] Naghizadeh, M. (2013) Representations of Beauty in Persian Gardens. Manzar: The Iranian Scientific Journal of Landscape, 5, 6-9.

[9] Irani Behbahani, H. (2007) Textbook of Development of Landscape Architecture Notions. Faculty of Environment, Tehran University.

[10] Hobhouse, P. (2003) Gardens of Persia. Mage Publishers, Washington DC.

[11] Khansari, M., Moghtader, M.R. and Yavari, M. (1998) The Persian Garden: Echoes of Paradise. Mage Publishers, Washington DC.

[12] Elmolhoda, H. (2003) Water in Iranian Architecture. Book of the Month: Art, No. 57, 86-87.

[13] Farokhyar, H. (1996) Paradise in Corner of Desert. Shahzdeh Hadi Board of Trustees Publications, Kashan, Iran, 11-139.

[14] Mahmoudi Farahani, L., Motamed, B. and Jamei, E. (2016) Persian Gardens: Meanings, Symbolism, and Design. Landscape Online, 46, 1-19

https://doi.org/10.3097/LO.201646

[15] Brookes, J. (1987) Gardens of Paradise: The History and Design of the Great Islamic Gardens. New Amsterdam Books, New York.

[16] Johnson, J., Sydney Johnson, J. and Links, J.A. (1929) The Persian Garden. Illustrated by Links, J.A., Windsor Press, England.

[17] Tousi, M. and Emamifar, S.N. (2011) Symbology and Semiotics of Persian Gardens' Elements According to Elements of Fin Garden in Kashan. Negara Scientific-Research Journal, No. 17. 
[18] Massoudi, A. (2009) Acquaintance with Iranian Gardens Bagh-e Shazdeh. Faza Publication, Tehran, 44.

[19] Farrokhyar, H.A. (1997) Paradise on the Margin of Kavir (Salt Desert). Teheran, 108.

[20] Zamani, E., Lillian, M.R., Amirkhani, A. and Okhovvat, H. (2009) Recognition and Analysis of the Place of Elements in the Iranian Garden with an Emphasis on Religious-Ritual Principles. Baq Nazar Publication, Iran, 38-25.

[21] Khansari, M. (1998) The Persian Garden: Echoes of Paradise. Mage Publishers, Washington DC.

[22] American Society of Landscape Architects (1977) Landscape Architecture. ASL Architects, USA.

Submit or recommend next manuscript to SCIRP and we will provide best service for you:

Accepting pre-submission inquiries through Email, Facebook, LinkedIn, Twitter, etc. A wide selection of journals (inclusive of 9 subjects, more than 200 journals)

Providing 24-hour high-quality service

User-friendly online submission system

Fair and swift peer-review system

Efficient typesetting and proofreading procedure

Display of the result of downloads and visits, as well as the number of cited articles

Maximum dissemination of your research work

Submit your manuscript at: http://papersubmission.scirp.org/

Or contact oje@scirp.org 